OPEN ACCESS

Edited by:

Carlos Roncero,

University of Salamanca, Spain

Reviewed by:

Kyoji Okita,

National Center of Neurology and

Psychiatry, Japan

Sara Dolan

Baylor University, United States

*Correspondence:

Jiemin Yang

yangjiemin85@126.com

Specialty section: This article was submitted to

Addictive Disorders,

a section of the journal

Frontiers in Psychiatry

Received: 12 November 2020 Accepted: 01 February 2021

Published: 19 February 2021

Citation:

Liu W, Tian Y, Yan X and Yang J (2021) Impulse Inhibition Ability With

Methamphetamine Dependents Varies at Different Abstinence Stages.

Front. Psychiatry 12:626535.

doi: 10.3389/fpsyt.2021.626535

\section{Impulse Inhibition Ability With Methamphetamine Dependents Varies at Different Abstinence Stages}

\author{
Weijun Liu ${ }^{1,2}$, Yu Tian ${ }^{1}$, Xinyu Yan ${ }^{1,2}$ and Jiemin Yang ${ }^{1 *}$ \\ 1 Institute of Brain and Psychological Sciences, Sichuan Normal University, Chengdu, China, ${ }^{2}$ Faculty of Psychology, \\ Southwest University, Chongaing, China
}

Objective: The purpose of this study is to evaluate whether the impulse inhibition ability with methamphetamine dependents would vary at different abstinence stages.

Methods: Sixty-three methamphetamine dependents, including 31 short-term $(<10$ months) and 32 long-term ( $\geq 10$ months) abstinence participants, were recruited for this study. In addition, 33 men were recruited as the healthy control $(\mathrm{HC})$ group. All participants performed a two-choice oddball task, which is well-established to assess impulse inhibition. Accuracy for deviant trials and deviant-standard reaction time (RT) delay were computed as indexes of impulse inhibition.

Results: The accuracy for deviant trials was significantly decreased in short-term abstinence subjects (90.61\%) compared to HC subjects $(95.42 \%, p<0.01)$, which was coupled with a shorter RT delay reflecting greater impulsivity in the short-term group vs. the HC group (47 vs. $73 \mathrm{~ms}, p<0.01$ ). However, impulse inhibition was improved in the long-term group, shown by the increased accuracy for deviant trials in the long-term group compared to the short-term group (94.28 vs. 90.61\%, $p<0.05$ ) and the similar accuracy for the long-term and $\mathrm{HC}$ groups $(p>0.05)$. Further regression analyses confirmed that the abstinence duration positively predicted impulse inhibition of methamphetamine dependents, both in accuracy and RT for deviant stimulus ( $\beta=0.294$, $p=0.019 ; \beta=0.337, p=0.007)$.

Conclusion: These results suggest that long-term abstinence is more effective in improving impulse inhibition with methamphetamine dependents.

Keywords: behavioral inhibition, impulsivity, methamphetamine, two-choice oddball, abstinence duration

\section{INTRODUCTION}

Impulsivity is defined as a predisposition toward rapid, unplanned reactions to internal, or external stimuli regardless of the potential negative consequences of these reactions (1-3). Impulsivity is associated with an increased likelihood of addiction (4), attention deficit hyperactivity disorder (5), and even antisocial behavior (6). Therefore, the ability to inhibit impulses is extremely important for humans.

Methamphetamine (MA) dependence induces impulsivity (7) and causes cognitive function decline (8). Previous research studies have investigated the negative impact of MA use in the Stop-signal task and Stroop task, showing a longer stop-signal RT (9) and higher error rate (10) in MA dependents. On the other hand, the MA dependent showed 
significantly worse performance on a test of processing speed (11). Moreover, evidence has shown that $56 \%$ of MA users have engaged in aggressive behaviors in social situations (12). These studies indicate that MA dependents have an impulse inhibition deficit.

Several studies have shown neural abnormalities in MA dependents, which can serve to promote impulsivity in MA dependents. One study showed that the basal ganglia of MA dependents were different from those of healthy humans; for example, they showed increased extracellular dopamine concentrations and reduced availability of dopamine transporter (DAT) (13). In addition, MA dependents were found to exhibit abnormal functional connectivity in the corticostriatal circuits, and the resting functional connectivity of the midbrain with the prefrontal cortex (PFC) in abstinent MA dependents was stronger than that in HC subjects (14). Interestingly, one study showed that no difference between long-term abstinent MA dependents and HCs in Stroop RT interference (15). In addition, one study found that a 2 -week period of withdrawal improved the right DAT binding and the executive control in MA dependents, suggesting an improvement of prefrontal cognitive control function after abstinence (16). Based on the evidence above, we hypothesized that long-term abstinence (i.e., 10 months or longer) may improve impulse inhibition in MA dependents. To test this hypothesis, the current study investigated the differences of impulse inhibition across different abstinence stages (shortterm and long-term) in MA dependents using the two-choice oddball task.

\section{METHODS}

\section{Participants}

Sixty-three MA dependents who met the Diagnostic and Statistical Manual of Mental Disorders (5th edition) criteria from Da Lian Shan Addiction Rehabilitation Center were recruited for the current study. They were received compulsory drug treatment when they were detected by police for last drug use, and they have no chance to use drug in the next 2 years. The eligibility criteria included no use of drugs other than MA, no physical disability, and no acute physical or psychiatric illness. The exclusion criteria included the use of multiple drugs, current medical conditions and medication use, and the receipt of brain stimulation therapy (Transcranial Direct Current Stimulation or Transcranial Magnetic Stimulation). To balance the sample size between short- and long-term groups, we designated 31 participants who had abstinence periods $<10$ months [mean $\pm \mathrm{SD},[6.17 \pm 2.60]$ months, median 7 months, range $0.17-$ 9 months] as the MA-short group; 32 participants who had abstinence durations $\geq 10$ months [mean $\pm \mathrm{SD},[13.13 \pm 1.93]$ months, median 13.17 months, range $10-17.17$ months] served as the MA-long group. The two groups were matched on variables related to history of MA use, such as maximum intake $(p>0.05)$, average intake weekly $(p>0.05)$, and years of MA use before abstinence $(p>0.05)$.

In addition, 33 healthy male participants were recruited as the HC group. The three groups were matched on demographic variables, such as age $(p>0.05)$, education $(p>0.05)$, alcohol use
( $p>0.05)$, smoking habits $(p>0.05)$, neuroticism $(p>0.05)$, and Barratt Impulsiveness Scale scores $(p>0.05)$ (Table 1).

All participants were right-handed and had normal or corrected-to-normal vision. All the participants participated in the study voluntarily and gave written informed consent. The study was approved by the local ethics committee of human research at Sichuan Normal University and Southwest University in China. The experimental procedures followed the ethical principles of the 1964 Declaration of Helsinki.

\section{Behavioral Task}

We used the two-choice oddball task to examine impulse inhibition, which involved the response to the standard stimulus involves habitual response while the response to the deviant stimulus involves inhibition of habitual motor response and the generation of a different motor response. This task provides both accuracy and response time as indicators of impulse inhibition (17-19).

In the two-choice oddball task, each trial started with a jittered fixation cross, varying from 500 to $1,500 \mathrm{~ms}$. Following this, the task stimulus was presented. For one-half of the participants in each treatment group, if the standard stimulus ("W"; $80 \%$ of trials) was presented, they were to press " $F$ " with their left index finger as quickly as possible. If the task stimulus was the deviant stimulus ("M"; $20 \%$ of trials), they were to press the "J" key with their right index finger. For the second half of the participants, the response keys were reversed (i.e., they were to press "J" for standard stimuli and "F" for deviant stimuli). Before the formal task, each participant had completed 15 practice trials to familiarize them with the procedure. To avoid the practice effect, the formal experiment did not start until participants had achieved 100\% accuracy for both standard and deviant stimuli during practice. At the end of the experiment, participants were told their accuracy as feedback on their performance. Behavioral impulsivity was primarily indicated by the levels of accuracy reduction (i.e., standard minus deviant stimuli accuracy, ACC cost), during deviant vs. standard trials (18). The deviant minus standard RT delay was also recorded to provide context for how ACC cost was altered.

\section{Statistical Analysis}

Where appropriate, one-way analysis of variance (ANOVA), student's $t$-test, and chi-square test were used to compare the differences in demographic variables among the $\mathrm{HC}$, short-term abstinence, and long-term abstinence groups. To analyze the impulse inhibition of participants in the two MA dependence groups compared with that of the HC group, the Bonferroni comparison was used for post-hoc comparisons after a statistically significant one-way ANOVA effect appeared. Linear regression was computed with duration of abstinence as predictor and accuracy for deviant stimulus, RT for deviant stimulus, ACC cost, or RT delay as the outcome, respectively. All statistical analyses were performed with SPSS 22.0 (IBM, Armonk, NY). 
TABLE 1 | Demographic Data (M \pm SD) of the Healthy Control Group, MA-Short, and MA-Long Abstinence Group.

\begin{tabular}{|c|c|c|c|c|c|}
\hline & HC $(n=33)$ & MA-short $(n=31)$ & MA-long $(n=32)$ & $F / \chi^{2} / t$ & $P$ \\
\hline Sex & Male & Male & Male & NA & NA \\
\hline Age (years) & $35.15 \pm 9.69$ & $39.03 \pm 5.90$ & $37.47 \pm 8.10$ & 1.87 & 0.16 \\
\hline BIS-11 & $57.06 \pm 8.45$ & $60.52 \pm 6.69$ & $59.88 \pm 7.00$ & 2.00 & 0.14 \\
\hline Neuroticism (Big Five Personality Inventory) & $31.53 \pm 8.52$ & $32.16 \pm 7.10$ & $32.81 \pm 7.13$ & 0.17 & 0.85 \\
\hline Smoking (\%) & 84.80 & 90.30 & 90.60 & 0.68 & 0.71 \\
\hline Alcohol use (\%) & 66.70 & 48.40 & 71.90 & 4.08 & 0.13 \\
\hline Education & $3.12 \pm .89$ & $2.48 \pm 1.15$ & $2.87 \pm 1.00$ & 9.11 & 0.33 \\
\hline Maximum intake (g) & NA & $0.70 \pm 0.46$ & $0.63 \pm 0.34$ & 0.71 & 0.48 \\
\hline Average intake weekly & NA & $2.31 \pm 2.02$ & $2.74 \pm 1.90$ & -0.86 & 0.39 \\
\hline Use duration (years) & NA & $6.81 \pm 3.37$ & $5.93 \pm 2.73$ & 1.13 & 0.27 \\
\hline
\end{tabular}

Unit for education: denoted as 1 for primary school, educated for 6 years; 2 for junior high school, educated for 9 years; 3 for senior high school, educated for 12 years; 4 for college, educated for 16 years; 5 for post-graduate, educated for 19 years. NA, means not available.

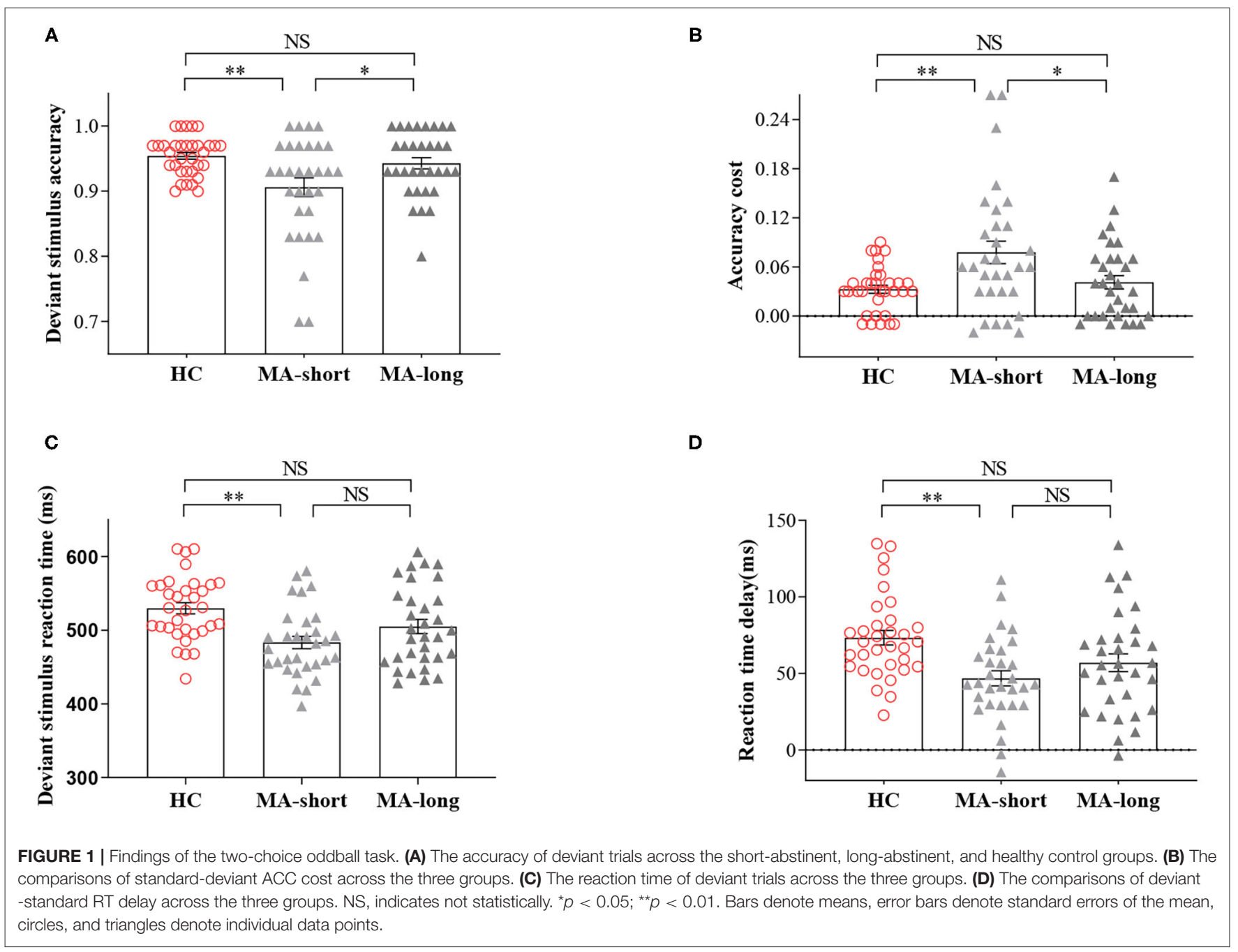




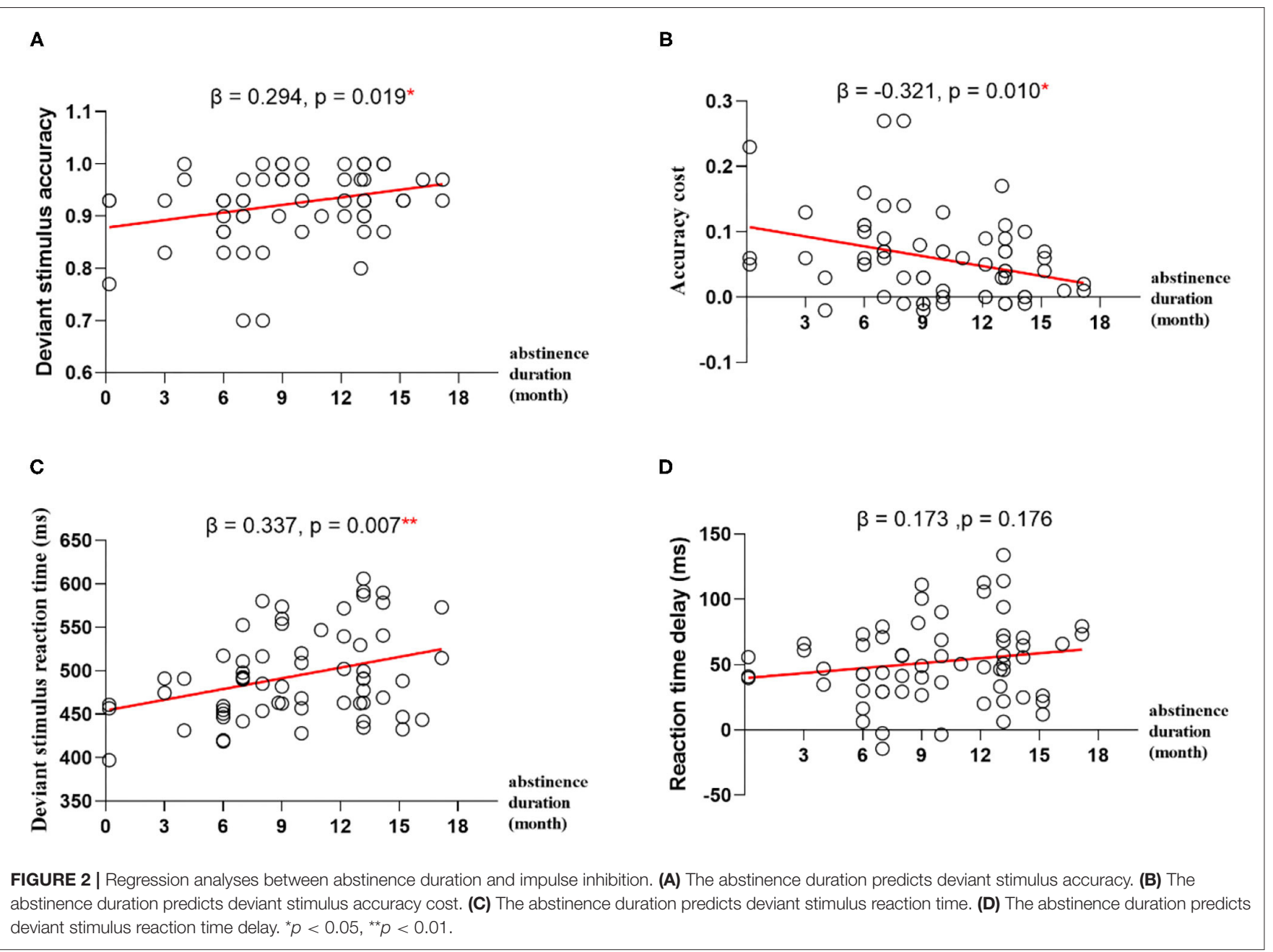

\section{RESULTS}

The three groups had significant differences in the accuracy of deviant trials $\left[\mathrm{F}_{(2,93)}=6.22, p<0.01\right]$ and in RT delay $\left[\mathrm{F}_{(2,93)}=\right.$ $6.67, p<0.01]$ and $\mathrm{ACC}$ cost $\left[\mathrm{F}_{(2,93)}=6.21, p<0.01\right]$.

Post-hoc pairwise comparisons showed lower accuracy for deviant trials in the MA-short group (90.61\%) compared to the HC group $(95.42 \%, p<0.01)$, indicating enhanced impulsivity in the former group. In addition, the MA-short group showed a shorter RT delay compared to the HC group (MA-short vs. HC, 47 vs. $73 \mathrm{~ms}, p<0.01$ ), suggesting the fast response tendencies of the MA-short group at the expense of the goal (correct response). However, the MA-long group ( $\mathrm{M}=94.28 \%)$ exhibited significantly higher accuracy during deviant trials compared to the MA-short group ( $M=90.61 \% ; p<0.05)$, which was confirmed by the analysis of ACC cost ( 4.10 vs. $7.80 \%, p<0.05$ ). In addition, the MA-long group and $\mathrm{HC}$ group showed no significant differences in accuracy of deviant trials, ACC cost, or RT delay.

It is worth noting that the MA-long group exhibited an RT delay similar to that of the MA-short group, suggesting that the accuracy improvement in the MA-long group was not at the expense of a greater RT delay (Figure 1).

\section{Regression Analyses}

To explore whether abstinence duration can predict the performance of impulse inhibition, we computed linear regression with duration of abstinence as predictor and accuracy for deviant stimulus, RT for deviant stimulus, ACC cost, or RT delay as outcome, respectively. The results showed that the abstinence duration positively predicted deviant stimulus ACCand RT $\left(\beta=0.294, p=0.019, \mathrm{R}^{2}=0.087 ; \beta=0.337, p\right.$ $\left.=0.007, \mathrm{R}^{2}=0.113\right)$, and the abstinence duration negatively predict ACC cost $\left(\beta=-0.321, p=0.010, \mathrm{R}^{2}=0.103\right)$ (Figure 2 ).

\section{DISCUSSION}

Our study demonstrated that impulse inhibition improved with long-term MA abstinence, and abstinence duration can effectively predict the impulse inhibition with MA dependents. On the one hand, our study showed that impulse inhibition deficits in naturally abstinent MA users lasted for about 10 
months after abstinence, and individuals in the MA-short abstinence group exhibited lower response accuracy and a shorter RT delay compared to the HC group. However, when the duration of abstinence lasted for more than 10 months, impulse inhibition improved to levels similar to those of the HC group, and the accuracy improvement was not at the expense of a greater RT delay. On the other hand, we also observed that the abstinence duration positively predicted impulse inhibition of MA dependents, both in ACC and RT for deviant stimulus.

Increasing evidence suggests the cognitive capacity and brain functions of the long-term abstinence can be improved in MA users (20). A longitudinal positron emission tomography study documented the improvement of striatal DAT loss in MA dependents within 12-17 months of abstinence (21) and the improvement of thalamic metabolism within a mean of 14 months of abstinence. In contrast, neither of these improvements were observed in short-term abstinence (22). However, none of the prior studies have directly examined what the abstinence duration affects MA-induced differences of impulse inhibition. Here, our study demonstrated that the MA-short abstinence group exhibited worse performance on the two-choice oddball task than the HC group, while these performances were not observed after 10 months of abstinence. These results suggest that it is important to provide more intervention resources to patients in the early stage of rehabilitation than the late stage, particularly concerning the reduction of impulsive drug reuse (23).

This study has several limitations. First, we only included male MA dependents because males were more likely to use MA. Considering the differences in behavioral impulsivity related to drug use between men and women (24), women should be recruited in future research. Second, this study used a cross-sectional approach, and the neural plasticity mechanisms supporting the improved impulse inhibition over time were unknown. Thus, future investigations employing longitudinal neural imaging are necessary.

\section{REFERENCES}

1. Moeller FG, Barratt ES, Dougherty DM, Schmitz JM, Swann AC. Psychiatric aspects of impulsivity. Am J Psychiatry. (2001) 158:178393. doi: 10.1176/appi.ajp.158.11.1783

2. Campbell RJ. Psychiatric dictionary, 6th ed. New York, NY: Oxford University Press (1989).

3. Dickman SJ. Impulsivity and information processing. In: McCown WG, Johnson JL, Shure MB, editors. The Impulsive Client: Theory, Research, and Treatment. Washington, DC: American Psychological Association (1993). p. 151-84. doi: 10.1037/10500-010

4. Kale D, Stautz K, Cooper A. Impulsivity related personality traits and cigarette smoking in adults: a meta-analysis using the UPPS-P model of impulsivity and reward sensitivity. Drug Alcohol Depend. (2018) 185:14967. doi: 10.1016/j.drugalcdep.2018.01.003

5. Winstanley CA, Eagle DM, Robbins TW. Behavioral models of impulsivity in relation to ADHD: translation between clinical and preclinical studies. Clin Psychol Rev. (2006) 26:379-95. doi: 10.1016/j.cpr.2006.01.001

6. Mann FD, Engelhardt L, Briley DA, Grotzinger AD, Patterson MW, Tackett JL, et al. Sensation seeking and impulsive traits as personality endophenotypes for
In summary, the present results suggest that behavioral inhibition deficits persist for about 10 months after MA abstinence. Long-term abstinence beyond 10 months may improve the patients' impulse inhibition to a level similar to that of the healthy population.

\section{DATA AVAILABILITY STATEMENT}

The raw data supporting the conclusions of this article will be made available by the authors, without undue reservation.

\section{ETHICS STATEMENT}

The studies involving human participants were reviewed and approved by Human Subjects Ethics Sub-committee of the Sichuan Normal University in China. The patients/participants provided their written informed consent to participate in this study.

\section{AUTHOR CONTRIBUTIONS}

WL, YT, and JY conceived and designed the study. WL data collection and statistical analyses. WL and JY data interpretation. WL, YT, XY, and JY wrote the final manuscript. All authors contributed to reviewed, and approved the final manuscript.

\section{FUNDING}

This study was funded by the National Natural Science Foundation of China through grants 31871103 and 31971018 to JY.

\section{ACKNOWLEDGMENTS}

We would like to thank Xinyu Cao for his assistance in interviewing the participants.

antisocial behavior: evidence from two independent samples. Pers Individ Dif. (2017) 105:30-9. doi: 10.1016/j.paid.2016.09.018

7. Jones HW, Dean AC, Price KA, London ED. Increased self-reported impulsivity in methamphetamine users maintaining drug abstinence. Am J Drug Alcohol Abuse. (2016) 42:500-6. doi: 10.1080/00952990.2016.11 92639

8. Dean AC, Groman SM, Morales AM, London ED. An evaluation of the evidence that methamphetamine abuse causes cognitive decline in humans. Neuropsychopharmacology. (2013) 38:259-74. doi: 10.1038/npp.2012.179

9. Monterosso JR, Aron AR, Cordova X, Xu J, London ED. Deficits in response inhibition associated with chronic methamphetamine abuse. Drug Alcohol Depend. (2005) 79:273-7. doi: 10.1016/j.drugalcdep.2005.02.002

10. Nestor LJ, Ghahremani DG, Monterosso J, London ED. Prefrontal hypoactivation during cognitive control in early abstinent methamphetamine-dependent subjects. Psychiatry Res. (2011) 194:287-95. doi: 10.1016/j.pscychresns.2011.04.010

11. Simon SL, Dean AC, Cordova X, Monterosso JR, London ED. Methamphetamine dependence and neuropsychological functioning: evaluating change during early abstinence. J Stud Alcohol Drugs. (2010) 71:335-44. doi: 10.15288/jsad.2010.71.335 
12. Brecht ML, Herbeck D. Methamphetamine use and violent behavior: user perceptions and predictors. J Drug Issues. (2013) 43:468-82. doi: 10.1177/0022042613491098

13. London ED, Kohno M, Morales AM, Ballard ME. Chronic methamphetamine abuse and corticostriatal deficits revealed by neuroimaging. Brain Res. (2015) 1628:174-85. doi: 10.1016/j.brainres.2014.10.044

14. Kohno M, Morales AM, Ghahremani DG, Hellemann G, London ED. Risky decision making, prefrontal cortex, and mesocorticolimbic functional connectivity in methamphetamine dependence. JAMA Psychiatry. (2014) 71:812-20. doi: 10.1001/jamapsychiatry.2014.399

15. Salo R, Nordahl TE, Galloway GP, Moore CD, Waters C, Leamon $\mathrm{MH}$. Drug abstinence and cognitive control in methamphetaminedependent individuals. J Subst Abuse Treat. (2009) 37:2927. doi: 10.1016/j.jsat.2009.03.004

16. Chou YH, Huang WS, Su TP, Lu RB, Wan FJ, Fu YK. Dopamine transporters and cognitive function in methamphetamine abuser after a short abstinence: a SPECT study. Eur Neuropsychopharmacol. (2007) 17:4652. doi: 10.1016/j.euroneuro.2006.05.002

17. Yuan J, He Y, Qinglin Z, Chen A, Li H. Gender differences in behavioral inhibitory control: ERP evidence from a two-choice oddball task. Psychophysiology. (2008) 45:986-93. doi: 10.1111/j.1469-8986.2008.00693.x

18. Yuan J, Xu M, Yang J, Li H. The application of the two-choice oddball paradigm to the research of behavioral inhibitory control. Sci Sin Vitae. (2017) 47:1065-73. doi: 10.1360/N052017-00125

19. Xin Z, Ting LX, Yi ZX, Li D, Bao ZA. Response inhibition of cigarette-related cues in male light smokers: behavioral evidence using a two-choice oddball paradigm. Front Psychol. (2015) 6:1506. doi: 10.3389/fpsyg.2015.01506

20. Hart CL, Marvin CB, Silver R, Smith EE. Is cognitive functioning impaired in methamphetamine users? A critical review. Neuropsychopharmacology. (2012) 37:586-608. doi: 10.1038/npp.2011.276
21. Volkow ND, Linda C, Gene-Jack W, Fowler JS, Dinko F, Mark $\mathrm{S}$, et al. Loss of dopamine transporters in methamphetamine abusers recovers with protracted abstinence. J Neurosci. (2001) 21:9414-8. doi: 10.1523/JNEUROSCI.21-23-09414.2001

22. Wang GJ, Volkow ND, Chang L, Miller E, Sedler M, Hitzemann R, et al. Partial recovery of brain metabolism in methamphetamine abusers after protracted abstinence. Am J Psychiatry. (2004) 161:242-8. doi: 10.1176/appi.ajp.16 1.2.242

23. Yuan J, Liu W, Liang Q, Cao $\mathrm{X}$, Lucas MV, Yuan TF. Effect of low-frequency repetitive transcranial magnetic stimulation on impulse inhibition in abstinent patients with methamphetamine addiction: a randomized clinical trial. JAMA Network Open. (2020) 3:e200910. doi: 10.1001/jamanetworkopen.202 0.0910

24. Scheffer M, Almeida RMMD. Alcohol consumption and differences between men and women: impulsive behavior, cognitive and neurochemistry aspects. Neuropsicol Lat. (2010). 2:1-11. Available online at: http://pepsic.bvsalud.org/ $\mathrm{pdf} / \mathrm{rnl} / \mathrm{v} 2 \mathrm{n} 3 / \mathrm{v} 2 \mathrm{n} 3 \mathrm{a} 01 . \mathrm{pdf}$

Conflict of Interest: The authors declare that the research was conducted in the absence of any commercial or financial relationships that could be construed as a potential conflict of interest.

Copyright $\odot 2021$ Liu, Tian, Yan and Yang. This is an open-access article distributed under the terms of the Creative Commons Attribution License (CC BY). The use, distribution or reproduction in other forums is permitted, provided the original author(s) and the copyright owner(s) are credited and that the original publication in this journal is cited, in accordance with accepted academic practice. No use, distribution or reproduction is permitted which does not comply with these terms. 